\title{
PEMANFAATAN PENDEKATAN BERORIENTASI LINGKUNGAN ILMU TEKNOLOGI MASYARAKAT (STM) UNTUK MENINGKATKAN KESADARAN SOSIAL DALAM PELESTARIAN LINGKUNGAN
}

\author{
Pipit Andriani 1, *, Wahyu Sukartiningsih², Waspodo Tjipto Subroto ${ }^{3}$ \\ 1, Universitas Negeri Surabaya \\ 2 Universitas Negeri Surabaya \\ ${ }^{3}$ Universitas Negeri Surabaya
}

\begin{abstract}
Abstrak
Penilaian tindakan kelas ini bertujuan untuk meningkatkan aktivitas siswa dan meningkatkan kesadaran sosial siswa melalui penggunaan pendekatan lingkungan yang berorientasi pada Ilmu Pengetahuan Teknologi Masyarakat dalam pelestarian lingkungan pada kelas V SDN Balas Klumprik I / 434 Surabaya. Penelitian tindakan kelas ini dilakukan dalam 3 siklus, masing-masing siklus meliputi tahapan perencanaan, pelaksanaan, observasi, dan refleksi. Hasil analisis data menunjukkan bahwa aktivitas siswa pada siklus I mencapai $76,2 \%$, pada siklus II meningkat menjadi $82,6 \%$, dan pada siklus III meningkat menjadi $85,9 \%$. Begitu juga dengan hasil analisis data kesadaran sosial siswa pada siklus I yang mencapai 79\%, pada siklus II meningkat menjadi $85 \%$, dan pada siklus ketiga meningkat menjadi $88 \%$. Berdasarkan hasil tersebut, dapat disimpulkan bahwa melalui penerapan pemanfaatan teknologi lingkungan pendekatan Community Community Technology untuk meningkatkan kesadaran sosial dalam pelestarian lingkungan dapat meningkatkan aktivitas dan kesadaran sosial siswa.
\end{abstract}

\author{
Keywords: \\ Ilmu Pengetahuan \\ Teknologi Masyarakat, \\ Sumber Daya \\ Pembelajaran \\ Lingkungan, Kegiatan \\ Siswa, Kesadaran Sosial
}

\section{PENDAHULUAN}

Perkembangan IPTEKS mencerminkan perkembangan kemampuan berpikir dan berkreasi manusia sebagai anggota masyarakat dan berdampak terhadap kehidupan global. Sejalan dengan pendapat (Srisawasdi \& Panjaburee, 2014; Wang, Vogel, \& Ran, 2011) yang menyatakan pendidikan IPS haruslah berangkat dari lingkungan agar mempunyai dampak yang baik bagi siswa. Bertolakbelakang dari harapan pendidikan IPS, hasil observasi yang dilakukan oleh peneliti di SDN Balas Klumprik pada siswa kelas V semester dua tahun 2015, didapati permasalah pembelajaran yang terjadi dalam mengajarkan materi IPS oleh guru adalah 1) kurangnya sumber belajar untuk mendukung pembelajaran IPS; 2) IPS menjadi mata pelajaran yang membosankan; 3) materi IPS dianggap mudah namun hasil belajarnya rendah; 4) pembelajaran IPS di sekolah berangkat dari topik-topik yang ada di buku teks; 5) siswa tidak tertarik dengan materi IPS.

Berangkat dari hasil observasi yang dilakukan peneliti, masalah utama dan pertama yang disinyalir menjadi pemicu ialah kurangnya sumber belajar untuk mendukung pembelajaran IPS. Hal ini sederhana namun mempunyai dampak besar dalam pembelajaran IPS. Terlebih ditemukan juga bahwa pembelajaran IPS di sekolah berangkat dari topik-topik yang ada di buku teks. Dua faktor ini yang bisa menjadi penyebab utama sehingga IPS kurang menarik di hati siswa. Padahal IPS merupakan mata pelajaran yang sangat menarik. Hal ini sejalan dengan pendapat (Srisawasdi \& Panjaburee, 2014) IPS akan sangat menarik jika pembelajarannya berangkat dari lingkungan sekitar. Banyak topik-topik materi IPS diangkat dari permasalahan lingkungan. Dari sinilah IPS akan menjadi isu hangat untuk dijadikan modal pembelajaran yang berwawasan masa depan.

Pemanfaatan lingkungan sebagai sumber belajar tidak banyak dilakukan oleh guru. Sering guru di sekolah termasuk di sekolah dasar, mengabaikan potensi-potensi lingkungan untuk dijadikan sumber

\footnotetext{
* Corresponding author.

E-mail Addresses: - pipit.afit1987@gmail.com (Pipit Andriani)
} 
belajar. Menyimak pendapat (Lowe, Whitman, \& Phillipson, 2009) dalam Journal of Applied Ecology, lingkungan menjadi sumber belajar yang konkret dan menyenangkan. Anak usia sekolah dasar sangat membutuhkan lingkungan sekitar agar pemahamannya dapat berfungsi secara maksimal. Hal serupa didukung pendapat (Bettencourt, Velho, \& Almeida, 2011; Ersay, 2015) dalam jurnal Procedia-Social and Behavioral Sciences, lingkungan akan sangat membantu dalam proses pembelajaran.

Diperlukan terobosan baru agar pembelajaran IPS dapat menarik minat belajar siswa. Salah satunya ialah dengan teknologi. Teknologi menjadi bagian tidak terpisahkan dalam era globalisasi modern ini. Berpandangan seirama dengan teori generasi, bahwa siswa sekarang merupakan generasi Z. Pada generasi Z (generasi yang lahir pada tahun 1995-2010), teknologi menjadi kebutuhan primer, bahkan sudah dikenal sebelum kelahiran. Mereka lahir dan dibesarkan di era digital, dengan aneka teknologi yang komplit dan canggih, seperti: komputer, laptop, Hand Phone, iPads, PDA, MP3 player, BBM, internet, dan aneka perangkat elektronik lainnya. Sejak kecil, mereka sudah mengenal (atau mungkin diperkenalkan) dan akrab dengan pelbagai gadget yang canggih, yang secara langsung atau pun tidak langsung akan berpengaruh terhadap perkembangan perilaku dan kepribadiannya. Menurut pendapat (Ilin \& Shestova, 2014; Levi, 2015) memperkirakan akan terjadi booming Generasi Z sekitar tahun 2020.

Teknologi menjadi pendukung lini kehidupan. Dalam rangka meningkatkan kualitas pembelajaran IPS, teknologi menjadi penting. Dengan memadukan dua konteks antara sumber belajar yang berangkat dari lingkungan dengan desain berbasis teknologi, tentu hal ini akan sangat membantu dalam pembelajaran. Untuk meningkatkan kualitas pembelajaran IPS yang secara otomatis akan meningkatkan kesadaran sosial dalam pelestarian lingkungan, peneliti tertarik untuk memanfaatkan lingkungan dan pendekatan Sains Teknologi Masyarakat (STM). STM sudah dikenal diberbagai belahan dunia, seperti yang sudah dilakukan oleh negara-negara maju seperti Singapura, dan Finlandia. STM mempunyai kelebihan dibanding dengan pendekatan lain yaitu unsur teknologinya. Dengan unsur teknologi dan masyarkat, konteks pembelajaran akan selalu kekinian sesuai perkembangan zaman. Senada dengan pendapat (Ersay, 2015; Yeh \& Fu, 2014) dalam jurnal Procedia-Social and Behavioral Sciences dan Eurasia Journal of Mathematics, Science and Technology Education bahwa dengan memanfaatkan lingkungan sebagai sumber belajar dan dikemas dengan basis teknologi masyarakat, tentu hal ini akan mempunyai dampak positif dalam pembelajaran khususnya IPS. Siswa akan dengan mudah mengenali lingkungan sekitar karena pembelajarannya berangkat dari dunia nyata anak.

Pada kenyataan di lapangan, dari hasil observasi bersama teman sejawat di SDN Balas Klumprik I/434 Surabaya, didapat 12 guru dari 18 guru kelas dalam pembelajarannya masih kurang bervariasi dalam menggunakan pendekatan pembelajaran, hal ini menyebabkan hasil belajar siswa menurun. Penurunan itu terlihat dari hasil ulangan akhir semester rata-rata kelas $\mathrm{V}$ pada tahun pelajaran 2014/2015 mencapai nilai 77, sedangkan pada tahun pelajaran 2015/2016 menurun menjadi 65.

Sementara untuk menanamkan suatu konsep, terutama dalam bidang ilmu sosial perlu diterapkan suatu pendekatan tertentu. Salah satu alasan guru kurang menggunakan metode atau pendekatan yang bervariasi disinyalir karena menuntut pemikiran, persiapan, dan pengelolaan kelas yang relatif sulit. Melalui observasi dan interview pada guru kelas V SDN Balas Klumprik I/434 Surabaya pada tahun pelajaran 2015/2016, ditemukan bahwa: (1) guru kurang menggunakan metode yang bervariasi; (2) guru kurang menguasai materi yang akan diajarkan. Pada Siswa Kelas V SDN Balas Klumprik I/434 Surabaya ditemukan: (1) siswa kurang menguasai konsep IPS khususnya pada tema lingkungan; (2) siswa belum aktif dalam proses pembelajaran; (3) hasil belajar tema lingkungan, siswa belum $85 \%$ mencapai KKM.

Mengacu pada hasil ulangan akhir semester tahun pelajaran 2015-2016, kelas V SDN Balas Klumprik I/434 Surabaya didapat nilai pada mata pelajaran IPS yang paling rendah dan tidak memenui standar KKM jika dilihat dari sisi muatan nasional. Nilai IPS rata-rata 65 atau sepuluh poin di bawah KKM yaitu 75. Hal ini tentu menjadi perhatian khusus bagi guru kelas. Terlebih peneliti termasuk guru kelas $\mathrm{V}$ di SDN Balas Klumprik I/434 Surabaya.

Berangkat dari latar belakang masalah dan pemikiran tersebut, peneliti ingin mengungkap dan memfokuskan penelitian pada pemanfaatan lingkungan berorientasi pendekatan Sains Teknologi Masyarakat (STM) untuk meningkatkan kesadaran sosial dalam pelestarian lingkungan. Dibanding pendekatan lain, seperti yang mengacu pada model kooperatif, STM belum pernah dilakukan di SDN Balas Klumprik I/434 Surabaya. Hal ini membuat STM akan meningkatkan daya ingin tahu siswa. Dengan demikian STM akan menjadi pengalaman baru untuk pembelajaran IPS.

\section{METODE}

Jenis penelitian yang digunakan dalam penelitian ini adalah Penelitian Tindakan Kelas (PTK). Menurut Iskandar (2013: 89), penelitian tindakan dalam pendidikan dilakukan melalui penelitian tindakan kelas. Penelitian Tindakan Kelas merupakan penelitian yang dilakukan oleh guru di dalam kelas 
sendiri melalui refleksi diri dengan tujuan memperbaiki kinerja sebagai guru, sehingga hasil belajar siswa menjadi meningkat (Wardani, 2008: 101). Penelitian tindakan kelas adalah penelitian yang dilakukan oleh guru, bekerja sama dengan peneliti lainnya (atau dilakukan sendiri oleh guru yang bertindak sebagai peneliti) di kelas atau di sekolah tempat dia mengajar dengan penekanan pada penyempurnaan atau peningkatan proses dan praktis pembelajaran.

Mengacu pada pandangan Kemmis dan Taggart (1988), penelitian tindakan dikerjakan melalui tiga tahap secara berdaur ulang (bersiklus), yaitu: (1) perencanaan tindakan; (2) pelaksanaan tindakan dan observasi menyatu dalam proses pembelajaran; (3) refleksi. Hal itu dilakukan sebagai rangkaian kegiatan pada setiap siklus. Selanjutnya berdasarkan hasil refleksi siklus pertama, apabila dipandang belum memenuhi ketuntasan pembelajaran, maka akan dilakukan perbaikan tindakan pembelajaran pada siklus kedua. Siklus PTK akan dihentikan jika didapat hasil pembelajaran memenuhi ketuntasan.

Subjek penelitian ini adalah siswa kelas V SDN Balas Klumprik I/434 Surabaya tahun pelajaran 2016-2017. Jumlah siswa sebanyak 30 orang, dengan rincian, 15 perempuan dan 15 laki-laki. Siswa kelas $\mathrm{V}$ mempunyai kemampuan yang heterogen. Secara umum siswa kelas V sudah bisa memanfaatkan teknologi dalam kesehariannya. Hal ini tentu mendukung dalam proses pembelajaran yang akan dilaksanakan. Sejalan dengan itu (Muhtadi, 2013; Riyanto, Sarwoko, \& Kushartantya, 2006) juga menyatakan bahwa siswa yang mempunyai keterampilan menggunakan teknologi sangatlah mendukung dalam proses pembelajaran. Segala informasi positif dengan mudah diakses oleh siswa yang terkategori melek teknologi.

Penelitian ini akan dilaksanakan di SDN Balas Klumprik I/434 Surabaya. Pemilihan tempat penelitian karena peneliti merupakan guru kelas V di SDN Balas Klumprik I/434 Surabaya. Dukungan oleh pihak sekolah untuk dijadikan tempat penelitian, agar sekolah terus termotivasi untuk meningkatkan mutu pembelajaran yang berbasis lingkungan dan teknologi adalah faktor pendukung yang kuat. Penelitian ini akan dilaksanakan pada tahun pelajaran 2016-2017.

Teknik pengumpulan data merupakan syarat bagi peneliti untuk mendapatkan data dari penelitiannya. Untuk memperoleh data yang dibutuhkan, teknik pengumpulan data yang digunakan dalam penelitian ini adalah sebagai berikut.

a. Tes

Tes sebagai instrumen pengumpulan data adalah serangkaian pertanyaan atau latihan yang digunakan untuk mengukur keterampilan, pengetahuan, intelegensi, kemampuan atau bakat, yang dimiliki oleh individu atau kelompok (Arikunto, 2013: 57). Dalam penelitian ini, tes bentuk evaluasi uraian menuntut jawaban berpikir tingkat tinggi dari siswa.

b. Observasi

Observasi atau pengamatan adalah suatu teknik yang dilakukan dengan cara mengadakan pengamatan secara teliti serta pencatatan secara sistematis (Arikunto, Suharjono, dan Supardi, 2008: 127). Dalam penelitian ini observasi digunakan untuk mengukur aktivitas siswa dalam belajar dan guru dalam mengajar.

Instrumen yang digunakan dalam penelitian ini ialah Lembar observasi aktivitas siswa . Menurut (Riyani, 2012) hal-hal yang diobservasi pada aktivitas siswa, meliputi: (1) siswa melaksanakan pembiasan; (2) siswa aktif saat guru membuka pembelajaran; (3) merespon stimulus yang disampaikan guru; (4) melakukan observasi lingkungan; (5) berdiskusi dalam kelompok dan mempresentasikan hasil diskusi/karya; (6) evaluasi dan penyimpulan materi.

Teknik analisis data dalam penelitian ini dilakukan sebagai berikut.

1. Aktivitas siswa selama pembelajaran dianalisis dengan menggunakan lembar observasi aktivitas siswa, dengan menentukan data frekuensi atau banyaknya siswa yang aktif selama pembelajaran dan disajikan dalam persentase keaktifan siswa setiap pertemuan.

2. Analisis hasil kesadaran sosial siswa

a. Ketuntasan individual

Ketuntasan individual dihitung dengan menggunakan rumus:

\section{Ketuntasan individual $\quad=\frac{\text { skor yang diperoleh }}{\text { skor total }} \times 100 \%$}

Hasil yang diperoleh kemudian dibandngkan dengan kriteria ketntasan Minimal (KKM). KKM yang ditetapkan pada mata pelajara IPS kelas $\mathrm{V}$ adalah sebesar 75 . Jika nilai individu kurang dari 75 berarti siswa belum tuntas dan apabila nilai yang diperoleh sama atau lebih dari 75 berarti siswa telah tuntas.

b. Ketuntasan Klasikal 
Ketuntasan klasikal dihitung dengan menggunakan rumus sebagai berikut.

Ketuntasan klasikal $=\frac{\sum \text { siswa yang twntas }}{\sum \text { siswa }} \times 100 \%$

Deskripsi ketuntasan klasikal dengan membandingkan hasil yang diperoleh. Apabila jumlah siswa tuntas sama atau lebih dari $80 \%$ berarti secara klasikal pembelajaran dikatakan tuntas, dan sebaliknya jika jumlah siswa yang tuntas belum mencapai $80 \%$ berarti secara klasikal belum tuntas.

\section{ANALISIS DAN PEMBAHASAN}

Penelitian "Pemanfaatan Lingkungan Berorientasi Pendekatan Sains Teknologi Masyarakat (STM) untuk Meningkatkan Kesadaran Sosial dalam Pelestarian Lingkungan Pada Siswa Kelas V SDN Balas Klumprik I/434 Surabaya" diharapkan mampu meningkatkan aktivitas siswa dalam pelaksanaan pembelajaran dengan pemanfaatan lingkungan berorientasi pendekatan Sains Teknologi Masyarakat dan meningkatkan kesadaran sosial dalam pelestarian lingkungan. Penelitian ini dikatakan berhasil apabila hasil penelitian aktivitas siswa mencapai keberhasilan $\geq 80 \%$ pada setiap aspek penilaian siswa secara klasikal mencapai 80\% dari seluruh siswa. Diskusi hasil penelitian ini berdasarkan pada rumusan masalah yang meliputi: 1) aktivitas siswa, 2) kesadaran sosial siswa dalam pelestarian lingkungan dengan pemanfaatan lingkungan berorientasi pendekatan Sains Teknologi Masyarakat.

A. Data Aktivitas Siswa

Sains Teknologi Masyarakat (STM) pendekatan yang dimaksudkan untuk mengetahui bagaimana sains dan teknologi masuk dan mengubah proses-proses sosial di masyarakat, dan bagaimana situasi sosial mempengaruhi perkembangan sains dan teknologi. Penerapan pendekatan STM pada pembelajaran mampu meningkatkan aktivitas siswa dalam proses pembelajaran dan meningkatkan kesadaran sosial siswa tehadap lingkungan. Siswa menjadi lebih aktif dan sadar secara sosial dalam melestarikan lingkungannya. Keberhasilan penggunaan pendekatan STM pembelajaran dapat dilihat dari adanya peningkatan aktivitas siswa yang dilakukan dari siklus I, Siklus II, dan siklus III. Data hasil aktivitas siswa yang diperoleh dari tindakan siklus I, II dan III dapat dilihat pada Tabel

Tabel 1

Perbandingan Aktivitas Siswa Siklus I, II, dan III

\begin{tabular}{|c|c|c|c|c|}
\hline \multirow[b]{2}{*}{ No. } & \multirow[b]{2}{*}{ Aspek } & \multicolumn{3}{|c|}{$\%$} \\
\hline & & Siklus I & Siklus II & $\begin{array}{c}\text { Siklus } \\
\text { III }\end{array}$ \\
\hline 1. & $\begin{array}{l}\text { Siswa melaksanakan } \\
\text { pembiasan. }\end{array}$ & 79,0 & 87,9 & 93,8 \\
\hline 2. & $\begin{array}{l}\text { Siswa aktif saat guru } \\
\text { membuka } \\
\text { pembelajaran. }\end{array}$ & 77,1 & 83,8 & 86,7 \\
\hline 3. & $\begin{array}{l}\text { Merespon stimulus } \\
\text { yang disampaikan } \\
\text { guru. }\end{array}$ & 75,6 & 82,5 & 85,0 \\
\hline 4. & $\begin{array}{l}\text { Melakukan observasi } \\
\text { lingkungan. }\end{array}$ & 74,8 & 83,3 & 86,9 \\
\hline 5. & $\begin{array}{lr}\text { Berdiskusi } & \text { dalam } \\
\text { kelompok } & \text { dan } \\
\text { mepresentasikan hasil } \\
\text { diskusi/karya. }\end{array}$ & 77,1 & 80,8 & 83,3 \\
\hline 6. & $\begin{array}{l}\text { Evaluasi dan } \\
\text { penyimpulan materi. }\end{array}$ & 73,5 & 77,1 & 79,4 \\
\hline
\end{tabular}


Dari Tabel 1. dapat diketahui adanya peningkatan aktivitas siswa dalam dari setiap aspek pengamatan. Berikut ini akan ditampilkan perbandingan secara klasikal persentase hasil observasi aktivitas siswa pada siklus I, siklus II, dan siklus III.

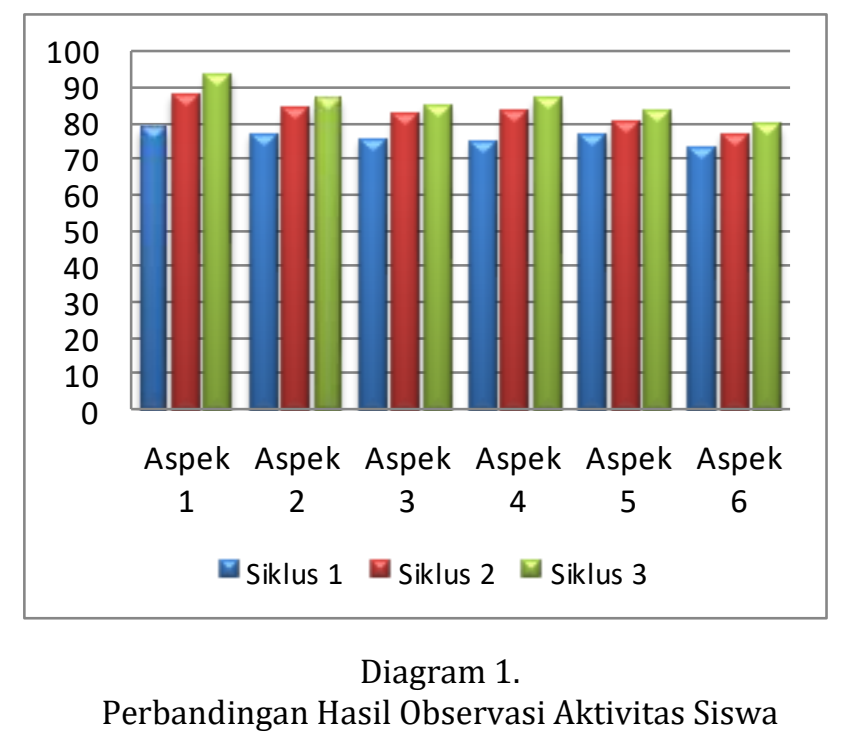

Berdasarkan diagram 1. maka dapat diketahui hasil observasi aktivitas siswa dalam setiap aspek mengalami peningkatan. Aspek 1 pada siklus I mencapai 79,0\% lalu pada siklus II meningkat menjadi 87,9\%, dan pada siklus III meningkat menajdi 93,8\%. Aspek 2 pada siklus I mencapai 77,1\%, pada siklus II mencapai $83,8 \%$, dan pada siklus III meingkat menjadi 86,7\%. Aspek 3 pada siklus I mencapai 75,6\%, dan pada siklus II meningkat menjadi 82,5\%, dan pada siklus III meningkat menjadi 85,0\%. Aspek 4 pada siklus I mencapai 74,8\%, pada siklus II mencapai $83,3 \%$, dan pada siklus III meningkat menjadi $86,9 \%$. Aspek 5 pada siklus I mencapai 77,1\%, pada siklus II meningkat menjadi $80,8 \%$, dan pada siklus III meningkat menjadi 83,3\%. Aspek 6 pada siklus I mencapai 73,5\%, pada siklus II mencapai 77,1\%, dan pada siklus III mencapai $79,4 \%$.

Data tersebut menunjukkan adanya peningkatan aktivitas siswa dalam penerapan pembelajaran STM dari siklus I, Siklus II, dan siklus III. Penjabaran diatas sesuai dengan apa yang dinyatakan oleh (Amir \& Nugroho, 2013; Chantaranima \& Yuenyong, 2014; Nakamura, 2010), bahwa STM dapat meningkatkan keterampilan proses, pemecahan, menekankan cara belajar yang baik yang mencakup ranah kognitif, afektif dan psikomotorik, dan menekankan sains dalam keterpaduan dan antara bidang studi.

Begitu juga dengan penggunaan media nyata dalam kegiatan pembelajaran sejalan dengan teori Behavioristik seperti apa yang dinyatakan oleh Thorndike bahwa belajar adalah proses interaksi antara stimulus dan respon. Stimulus adalah apa yang merangsang terjadinya kegiatan belajar seperti pikiran, perasaan, atau hal-hal lain yang dapat ditangkap melalui alat indera (dalam Rachman, 2015). Rachman (2015) juga menjelaskan bahwa dalam teori konstruktivis seseorang harus membangun sendiri pengetahuannya secara aktif. Dalam teori ini bertujuan untuk mengembangkan kemampuan siswa untuk mengajukan pertanyaan dan mencari sendiri pertanyaannya, membantu siswa untuk mengembangkan pengertian dan pemahaman konsep secara lengkap, mengembangkan kemampuan siswa untuk menjadi pemikir yang mandiri, dan lebih menekankan pada proses belajar bagaimana belajar itu.

Berdasarkan penjelasan tersebut dapat diketahui bahwa terdapat keterkaitan antara penerapkan STM dengan peningkatan aktivitas dan kesadaran sosial siswa dalam melestarikan lingkungan.

\section{B. Data Kesadaran Sosial Siswa}

Tujuan utama dari penerapan STM dalam pembelajaran adalah meningkatkan kesadaran sosial siswa. Hal ini sejalan dengan tujuan pendekatan STM. Menurut (Kumar \& Berlin, 1998; Xiong et al., 2013), pendekatan STM diartikan sebagai pembelajaran yang dirancang dengan menggunakan isu-isu sosial dan teknologi yang ada di lingkungan siswa sebagai pemicu dalam pembelajaran suatu konsep. Berikut ini akan disajikan data hasil penilaian kesadaran sosial siswa dengan pendekatan STM. 
Tabel 2

Perbandingan Penilaian Kesadaran Sosial Siswa Siklus I, II, dan III

\begin{tabular}{|c|c|c|c|c|c|c|}
\hline \multicolumn{7}{|c|}{ Persentase \% } \\
\hline \multicolumn{3}{|c|}{ Siklus I } & \multicolumn{2}{|c|}{ Siklus II } & \multicolumn{2}{|c|}{ Siklus III } \\
\hline Cukup & Baik & $\begin{array}{c}\text { Sangat } \\
\text { Baik }\end{array}$ & Baik & $\begin{array}{c}\text { Sangat } \\
\text { Baik }\end{array}$ & Baik & $\begin{array}{c}\text { Sangat } \\
\text { Baik }\end{array}$ \\
\hline $7 \%$ & $43 \%$ & $50 \%$ & $30 \%$ & $70 \%$ & $7 \%$ & $93 \%$ \\
\hline \multicolumn{3}{|c|}{$79 \%$} & \multicolumn{2}{|c|}{$85 \%$} & \multicolumn{2}{|c|}{$88 \%$} \\
\hline
\end{tabular}

Dari data Tabel 2 di atas, diketahui bahwa persentase tingkat kesadaran sosial siswa secara klasikal setelah penerapan pendekatan STM dari siklus I, II, dan siklus III mengalami peningkatan. Pada siklus I tingkat kesadaran sosial siswa mencapai 79\%, sedangkan pada siklus II meningkat menjadi 85\%, dan pada siklus III kembali mengalami peningkatan menjadi 88\%. Hal ini sejalan dengan pendapat (Srisawasdi \& Panjaburee, 2014), yang menyatakan bahwa Sains Teknologi Masyarakat (STM), dapat meningkatkan kesadaran sosial dalam upaya pelestarian lingkungan.

Berdasarkan Tabel 2 dapat disajikan perbandingan persentase penilaian kesadaran sosial siswa pada setiap siklus dalam bentuk diagram.

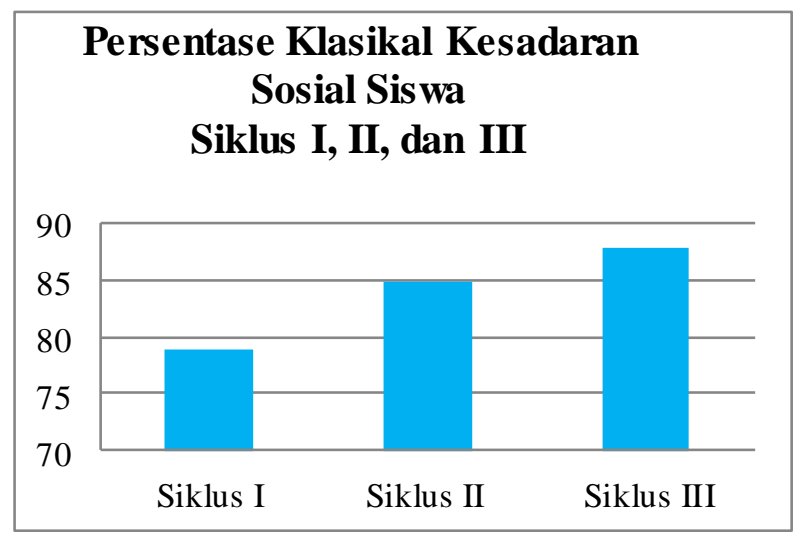

Gambar 2 Diagram Perbandingan Kesadaran Sosial Siswa Siklus I, II, dan III

Dari diagram 2 diatas diketahui bahwa persentase tingkat kesadaran sosial siswa secara klasikal setelah penerapan pembelajaran STM dari siklus I, siklus II, dan siklus III mengalami peningkatan. Pada siklus I tingkatan aktivitas kesadaran sosial siswa mencapai 79\%, sedangkan pada siklus II meningkat menjadi 85\%, dan pada siklus III kembali mengalami peningkatan menjadi 88\%.

\section{SIMPULAN DAN SARAN}

Dari hasil analisis data dan diskusi hasil dapat disimpulkan sebagai berikut. 1) Aktivitas siswa dalam pelaksanaan pembelajaran dengan pemanfaatan lingkungan berorientasi pendekatan Sains Teknologi Masyarakat dapat meningkatkan kesadaran sosial dalam pelestarian lingkungan. Rata-rata persentase ketercapaian pada siklus I sebesar 76,2\% (baik), meningkat pada siklus II menjadi 82,6\% (sangat baik), dan pada siklus III mengalami peningkatan menjadi 85,9\%, 2) Kesadaran sosial dalam pelestarian lingkungan dengan pemanfaatan lingkungan berorientasi pendekatan Sains Teknologi Masyarakat mengalami peningkatan. Rata-rata tingkatan kesadaran sosial siswa pada siklus I sebesar 79\% (baik), meningkat pada siklus II menjadi 85\% (sangat baik), dan pada siklus III kembali mengalami peningkatan menjadi $88 \%$ (sangat baik).

Berdasarkan hasil penelitian "Pemanfaatan Lingkungan Berorientasi Pendekatan Sains Teknologi Masyarakat (STM) untuk Meningkatkan Kesadaran Sosial dalam Pelestarian Lingkungan Pada Siswa Kelas V SDN Balas Klumprik I/434 Surabaya", berikut ini akan disampaikan beberapa saran yang terkait. 1) Guru sebaiknya menggunakan pendekatan STM untuk meningkatkan aktivitas siswa dalam pelestarian lingkungan. Hal ini karena siswa akan berlatih secara langsung terhadap permasalahan lingkungan 
dengan mengaitkan pada sains dan teknolgi masyarakat, 2) Guru sebaiknya menggunakan pendekatan STM untuk meningkatkan kesadaran sosial siswa dalam melestarikan lingkungan, 3) Guru sebaiknya memanfaatkan lingkungan sebagai sumber dan media belajar dalam pelestarian lingkungan.

\section{DAFTAR PUSTAKA}

Aibar, E. (2010). A critical analysis of information society conceptualizations from an STS point of view. tripleC-Cognition, Communication, Co-Operation, 8(2), 177-182. Retrieved from http://www.uoc.edu/webs/eaibar/_resources/documents/Aibar_critical.pdf

Akcay, H., \& Yager, R. E. (2010). The Impact of a Science/Technology/Society Teaching Approach on Student Learning in Five Domains. Journal of Science Education and Technology, 19(6), 602-611.

Amir, S., \& Nugroho, Y. (2013). Beyond the Triple Helix: Framing STS in the Developmental Context. Bulletin of Science, Technology \& Society, 33(3-4), 115-126. https://doi.org/10.1177/0270467613509603

Arikunto, Suharsimi. (2007). Dasar-Dasar Evaluasi Pendidikan. Jakarta: PT Bumi Aksara.

Arikunto, Suharsimi. (2013). Dasar-Dasar Evaluasi Pendidikan. Jakarta: PT Bumi Aksara.

Arikunto, Suhardjono, dan Supardi. (2008). Penelitian Tindakan Kelas. Jakarta: Sinar Grafika.

Bettencourt, C., Velho, J. L., \& Almeida, P. A. (2011). Biology teachers' perceptions about ScienceTechnology-Society (STS) education. In Procedia - Social and Behavioral Sciences (Vol. 15, pp. 31483152).

Chantaranima, T., \& Yuenyong, C. (2014). The Outcomes of Teaching and Learning About Sound Based on Science Technology and Society ( STS ) Approach. Procedia - Social and Behavioral Sciences, 116, 2286-2292. https://doi.org/10.1016/j.sbspro.2014.01.561

Effendi, S. A. (2011). Implementasi Kearifan Lingkungan Dalam Budaya Masyarakat Adat Kampung Kuta Sebagai Sumber Pembelajaran Ips. Jurnal Penelitian Pendidikan, Khusus(2), 164-177.

Erni, E. (2015, June 29). EVALUASI RENCANA PEMBELAJARAN IPS SD DAN UPAYA PERBAIKANNYA PADA MAHASISWA PGSD. Jurnal Teknologi Informasi Komunikasi Pendidikan. Retrieved from http://jurnal.fkip.unila.ac.id/index.php/JTP/article/view/9191

Ersay, E. (2015). Investigating Pre-Service Early Childhood Teachers' Views on Science Technology and Society Issues in Turkey. Procedia - Social and Behavioral Sciences, 191, 1397-1402. https://doi.org/10.1016/j.sbspro.2015.04.318

Garforth, L. (2012). In/Visibilities of Research: Seeing and Knowing in STS. Science, Technology \& Human Values, $\quad 37(2), \quad 264-285 . \quad$ Retrieved from http://sth.sagepub.com/content/37/2/264\%5Cnhttp://sth.sagepub.com/content/37/2/264.short

Ilin, I., \& Shestova, T. (2014). Z-Generation. Value Inquiry Book Series, 276, 500. Retrieved from http://search.ebscohost.com/login.aspx?direct=true\&db=a9h\&AN=97490600\&site=ehost-live

Jensen, C. B. (2013). Continuous Variations: The Conceptual and the Empirical in STS. Science, Technology \& Human Values, 39(2), 192-213. Retrieved from http://sth.sagepub.com/content/39/2/192.abstract

Jensen, C. B., Lauritsen, P., \& Olesen, F. (2007). Introduktion til STS: Science, technology, society. Introduktion til STS - Science, technology, society (Vol. 1. udg., udg.1). https://doi.org/10.4103/09724923.73809

Kaya, O. N., Yager, R., \& Dogan, A. (2009). Changes in Attitudes Towards Science-Technology-Society of Pre-service Science Teachers. Research in Science Education, 39(2), 257-279.

Kumar, D., \& Berlin, D. (1998). A Study of STS Themes in State Science Curriculum Frameworks in the United States. Journal of Science Education and Technology, 7(2), 191-197. Retrieved from http://www.jstor.org/stable/40186462\%5Cnhttp://www.jstor.org.ezproxy.bu.edu/stable/pdfplus/ 40186462.pdf?acceptTC=true 
LEVI, A. (2015). Make Way for Generation Z. New York Times, 164(56820), 7. Retrieved from http://search.ebscohost.com/login.aspx?direct=true\&db=a9h\&AN=101786861\&site=ehost-live

Lowe, P., Whitman, G., \& Phillipson, J. (2009). Ecology and the social sciences. Journal of Applied Ecology, 46(2), 297-305.

Muhtadi, A. (2013). Pemanfaatan Teknologi Informasi untuk Meningkatkan Kualitas dan Efektifitas Pendidikan. Muslim, (iii), 1-11. Retrieved from http://staff.uny.ac.id/sites/default/files/132280878/8. Pemanfaatan TI untuk meningkatkan kualitas dan efektivitas pembelajaran.pdf

Nakamura, M. (2010). STS in Japan in light of the science caf?? movement. East Asian Science, Technology and Society, 4(1), 145-151.

Riyani, Y. (2012). Faktor-faktor yang Mempengaruhi Prestasi Belajar Mahasiswa. Jurnal EKSOS, 8(1), 1925. Retrieved from http://repository.polnep.ac.id/xmlui/bitstream/handle/123456789/354/03YANI R.pdf?sequence=1

Riyanto, D. E., Sarwoko, E. A., \& Kushartantya. (2006). E-Learning Sebagai Model Proses Pembelajaran Berbasis Teknologi Informasi. Seminar Nasional SPMIPA 2006, 1-7.

Schubert, C. (2011). In the Middle of Things. Germany' s ongoing Engagement with STS. TECNOSCIENZA: Italian Journal of Science \& Technology Studies, 2(2), 103-113. Retrieved from http://www.tecnoscienza.net/index.php/tsj/article/view/82

Srisawasdi, N., \& Panjaburee, P. (2014). Technology-enhanced Learning in Science, Technology, and Mathematics Education: Results on Supporting Student Learning. Procedia - Social and Behavioral Sciences, 116, 946-950. https://doi.org/10.1016/j.sbspro.2014.01.325

Sudijono, Anas. (2010). Pengantar Statistik Pendidikan. Jakarta: PT Radjagrafindo Persada.

Vázquez-Alonso, Á., García-Carmona, A., Manassero-Mas, M. A., \& Bennàssar-Roig, A. (2013). Spanish Secondary-School Science Teachers' Beliefs About Science-Technology-Society (STS) Issues. Science and Education, 22(5), 1191-1218.

Wang, M., Vogel, D., \& Ran, W. (2011). Creating a performance-oriented e-learning environment: A design science approach. Information \& Management, 48(7), 260-269. https://doi.org/10.1016/j.im.2011.06.003

Widyaningrum, R., Sarwanto, \& Karyanto, P. (2013). PENGEMBANGAN MODUL BERORIENTASI POE (PREDICT, OBSERVE, EXPLAIN) BERWAWASAN LINGKUNGAN PADAMATERI PENCEMARAN UNTUK MENINGKATKAN HASIL BELAJAR SISWA. BIOEDUKASI, 6(1), 100-117.

Xiong, H., Fu, D., Duan, C., Liu, C. E., Yang, X., \& Wang, R. (2013). Current status of green curriculum in higher education of Mainland China. Journal of Cleaner Production, 61, 100-105.

Yager, R. E. ., \& Akcay, H. (2008). Comparison of \{Student $\{$ Learning $\{$ Outcomes $\}$ in $\{$ Middle $\}$ School $\}$ \{Science $\{$ Classes $\}$ with an $\{$ STS $\}$ AApproach $\}$ and a $\{$ Typical $\}$ TTextbook $\}$ Dominated $\}$ Approach\}. Research in Middle Level Education Online, 31(7), 1-16. https://doi.org/Article

Yeh, S. P., \& Fu, H. W. (2014). Effects of cooperative E-Learning on learning outcomes. Eurasia Journal of Mathematics, Science and Technology Education, 10(6), 531-536. 